\title{
Cardiopulmonary
}

Support

and Physiology

\section{Cardiac nociceptive reflexes after transmyocardial laser revascularization: Implications for the neural hypothesis of angina relief}

Anthony J. Minisi, MDa

On Topaz, MDa

M. Susan Quinn ${ }^{\text {a }}$

Laxmi B. Mohanty, MD

See related editorial on page 647 .

From the Departments of Internal Medicine $\left(\right.$ Cardiology) ${ }^{\mathrm{a}}$ and Pathology, ${ }^{\mathrm{b}}$ Medical College of Virginia, Campus of Virginia Commonwealth University, and Hunter Holmes McGuire Department of Veterans Affairs Medical Center, Richmond, Va.

Received for publication Jan 11, 2000; revisions requested July 7, 2000; revisions received April 19, 2001; accepted for publication April 24, 2001.

Address for reprints: Anthony J. Minisi, MD, Cardiology Section (111J1), McGuire VA Medical Center, 1201 Broad Rock Blvd, Richmond, VA 23249 (E-mail: Minisi.Anthony_J.@Richmond.VA.Gov).

J Thorac Cardiovasc Surg 2001;122:712-9 12/1/116946

doi: $10.1067 / \mathrm{mtc} .2001 .116946$

Objective: The mechanism by which transmyocardial laser revascularization relieves angina is not understood. One theory is that laser-induced thermal damage to cardiac nerves results in cardiac denervation. This study examined the acute effects of transmyocardial laser revascularization on reflex responses mediated by cardiac nociceptors, the left ventricular receptors with sympathetic afferent fibers that are thought to mediate anginal chest pain.

Methods: Experiments were performed in 13 chloralose-anesthetized dogs with sinoaortic denervation and vagotomy. Left ventricular receptors with sympathetic afferent fibers were activated by epicardial and intracoronary bradykinin before and 45 minutes after transmyocardial laser revascularization. Reflex responses elicited by bradykinin were quantitated by direct recording of efferent renal sympathetic nerve activity. Transmyocardial laser revascularization was performed in the openchest model with a hand-held holmium:YAG laser (2.1- $\mu$ m wavelength).

Results: An average of $44.5 \pm 1.0$ channels were created. Before transmyocardial laser revascularization, reflex increases in renal sympathetic nerve activity were elicited by both epicardial and intracoronary bradykinin. After transmyocardial laser revascularization, there was no significant attenuation in the reflex responses to either epicardial (before, $66 \% \pm 8 \%$; after, $100 \% \pm 24 \% ; P=.19$ ) or intracoronary (before, $124 \% \pm 37 \%$; after, $108 \% \pm 25 \% ; P=.44$ ) bradykinin.

Conclusions: Transmyocardial laser revascularization has no significant short-term effect on reflexes mediated by left ventricular receptors with sympathetic afferent fibers in anesthetized dogs. These results indicate that transmyocardial laser revascularization does not acutely interrupt the afferent nerves, which are believed to transmit the perception of anginal pain.

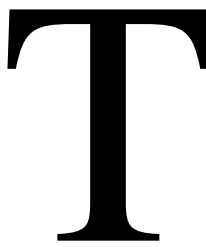

ransmyocardial laser revascularization (TMLR) has emerged as a promising therapeutic modality for the relief of angina in severely symptomatic patients who are not candidates for surgical or percutaneous revascularization. TMLR has been shown to improve subjective symptoms of ischemia in these patients. ${ }^{1-4}$ The mechanism or mechanisms underlying the beneficial effect of TMLR are not completely understood. TMLR has been shown to improve objective parameters of myocardial perfusion, ${ }^{1,4,5}$ but the improvement in subjective symptoms may be related to modification of the perception of cardiac pain. 
The sensation of cardiac pain associated with myocardial ischemia is believed to be mediated by activation of left ventricular receptors with sympathetic afferent fibers. ${ }^{6,7}$ These receptors are located throughout the left ventricle, but they are distributed mainly in the superficial epicardial layers. ${ }^{8-10}$ These receptors are polymodal in that they can be activated by both mechanical and chemical stimuli. ${ }^{11-13}$ During coronary occlusion, they can be activated by increases in cardiac pressures and by release of noxious chemicals from the ischemic myocardium. In addition to the sensation of cardiac pain, activation of these receptors results in reflex excitatory responses, such as hypertension, tachycardia, and vasoconstriction. ${ }^{14-16}$ These reflex excitatory responses are produced by increases in efferent sympathetic outflow and decreases in efferent parasympathetic outflow from the central nervous system.

It has been postulated that laser-induced thermal damage to cardiac receptors with sympathetic afferent fibers may be a potential mechanism for the relief of angina after TMLR. There is anatomic evidence of left ventricular sympathetic denervation after TMLR in both human subjects and experimental animals. ${ }^{17,18}$ However, previous studies that have evaluated the functional consequences of TMLR on left ventricular receptors with sympathetic afferent fibers have been limited by methodologic shortcomings. ${ }^{17}$ We performed experiments to reassess the short-term effects of TMLR on the function of left ventricular receptors with sympathetic afferent fibers. We used experimental techniques that facilitated the rigorous analysis of reflexes mediated by these receptors. We hypothesized that if TMLR caused significant left ventricular sympathetic deafferentation, then reflex excitatory responses elicited by chemical activation of these receptors would be decreased or abolished.

\section{Methods}

Experiments were performed in 13 anesthetized, mechanically ventilated dogs with sinoaortic denervation and vagotomy. The dogs were anesthetized with sodium thiopental $(25-35 \mathrm{mg} / \mathrm{kg}$ administered intravenously), followed by $\alpha$-chloralose $(80 \mathrm{mg} / \mathrm{kg}$ administered intravenously). Supplemental doses of chloralose (10 $\mathrm{mg} / \mathrm{kg}$ administered intravenously) were given hourly. The dogs' lungs were ventilated with a combination of oxygen and room air. The femoral artery and vein were cannulated for continuous measurement of arterial pressure and for infusion of drugs. Body temperature was maintained by external warming with both a heating blanket and a heating lamp. All procedures and anesthetic techniques were reviewed and approved by the Institutional Animal Care and Use Committee of Virginia Commonwealth University as being in compliance with "The Guide for Care and Use of Laboratory Animals."

\section{Surgical Preparation}

Sinoaortic denervation and cervical vagotomy were performed in all animals to facilitate the study of reflexes mediated by left ven- tricular receptors with sympathetic afferent fibers. These procedures eliminate the effects of reflexes mediated by the arterial baroreflex and the vagal cardiopulmonary reflex. A midline cervical incision was made to expose the carotid arteries and cervical vagi bilaterally. The carotid baroreceptors were denervated by means of isolation, ligation, and sectioning of all structures that course between the internal and external carotid arteries. Adequate carotid sinus denervation was confirmed by lack of renal nerve traffic and arterial pressure changes during transient, bilateral carotid occlusion. Cardiopulmonary receptors with vagal afferent fibers and the aortic arch baroreceptors were denervated by means of sectioning of the cervical vagus sheath containing the vagus and aortic depressor nerves bilaterally. Previous studies indicate that the technique of cervical vagotomy abolishes reflex responses mediated by the vagal cardiopulmonary afferents and the aortic arch baroreceptors. ${ }^{19-21}$

Next, an incision was made in the left fifth intercostal space, and the heart was suspended in a pericardial cradle. A small cannula (PE-50) was placed into a diagonal branch of the left anterior descending coronary artery for injection of bradykinin. Care was taken to keep the surface of the heart warm and moist.

\section{Renal-Nerve Recordings}

An incision was made in the left flank to expose the left renal artery. By means of an operating microscope, a small branch of the renal sympathetic nerves was dissected free from the renal artery and the surrounding connective tissue. The nerve was sectioned distally, and the nerve sheath was removed. The nerve was immersed in mineral oil and placed on bipolar platinum-iridium electrodes for the recording of action potentials, as described in detail previously. ${ }^{22}$ In brief, the signal was amplified by a bandpass amplifier (model P511; Grass Instruments, West Warwick, RI) with high-frequency cutoff set at 1000 to $3000 \mathrm{~Hz}$ and lowfrequency filter set at 30 to $100 \mathrm{~Hz}$. The output of the amplifier was fed into an audio amplifier and a spike counter that tabulated spike firing frequency by counting all nerve-spike activity with amplitudes exceeding a preselected voltage level (just above the noise band).

\section{TMLR Procedure}

We performed TMLR in our experimental animals according to the protocol that has been used in human subjects. ${ }^{3}$ A solid-state, 12$\mathrm{W}$, pulsed holmium:YAG laser $(2.1-\mu \mathrm{m}$ wavelength; Eclipse Surgical Technologies Inc, Sunnyvale, Calif) was used to create transmyocardial channels. The laser was calibrated to deliver 6 to $8 \mathrm{~W}$ per pulse. Laser energy was delivered at a rate of 5 pulses per second through a flexible 1-mm optical fiber. Laser firing was not gated to the cardiac cycle. Laser channels were made under direct visualization of the target area in the open-chest model. The density of the channels was approximately one per square centimeter. The depth setting on the hand-held laser catheter was placed at 2.5 $\mathrm{cm}$ to ensure that the fiber completely traversed the ventricular wall. In addition, an audible change in the firing of the laser was perceptible when the left ventricular cavity was entered. Creation of these channels was routinely associated with bleeding, but in all cases hemostasis could be obtained with digital pressure for 1 to 2 minutes. A mean of $44.5 \pm 1.0$ channels was made throughout the left ventricle. However, because receptors were activated by chem- 

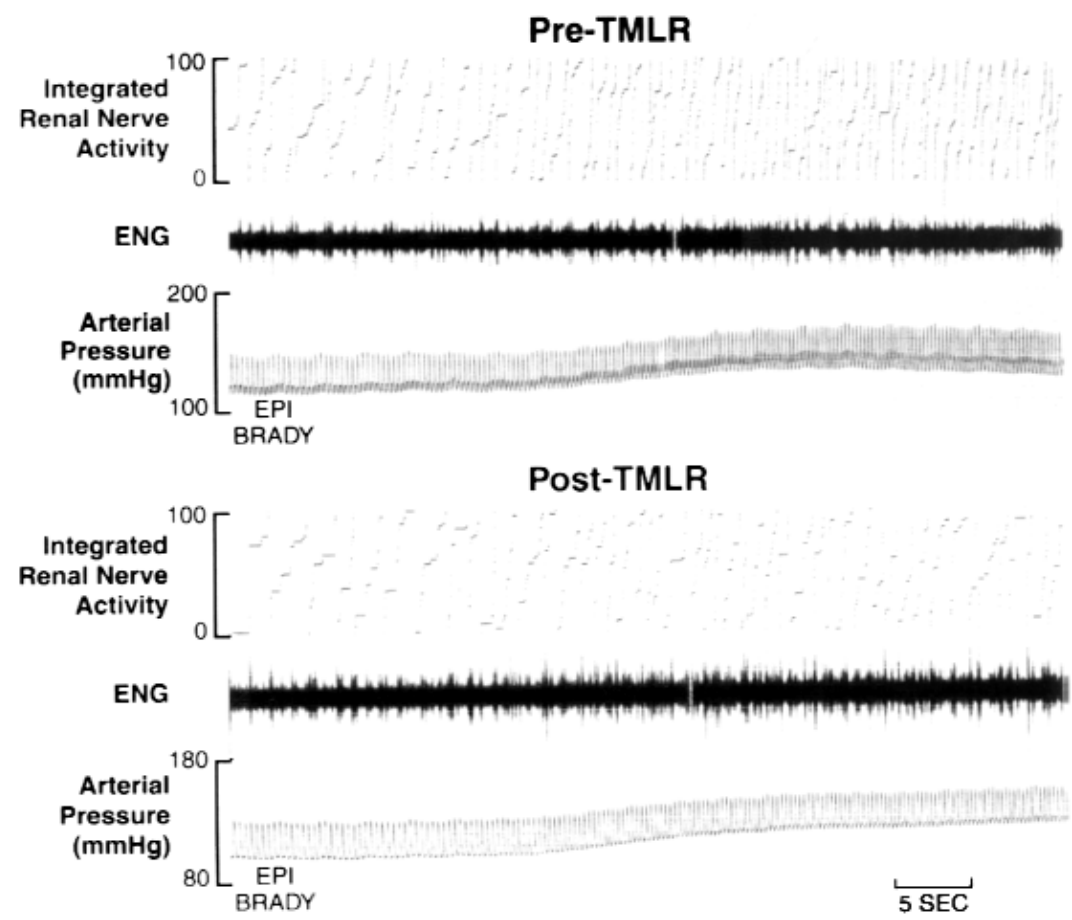

Figure 1. Original experimental record showing the changes in arterial pressure, raw renal nerve activity (ENG), and integrated renal-nerve activity (spike-firing frequency) in response to epicardial bradykinin (Epi Brady). Responses were measured before (top panel) and after (bottom panel) TMLR. The time of epicardial bradykinin application is denoted by the label "Epi Brady."

icals administered in the distribution of the anterior descending artery, the majority of channels were created in the anterior, anterolateral, and apical regions. A mean of $1491 \pm 115$ laser pulses was delivered during each procedure. At the completion of all experiments, the heart was removed and examined. This confirmed that the laser channels were completely transmural.

\section{Experimental Protocol}

The reflex changes in arterial pressure and renal sympathetic nerve activity (RSNA) elicited by chemical activation of left ventricular receptors with sympathetic afferent fibers were measured in the baseline state and after TMLR. Left ventricular sympathetic afferents were activated by both epicardial and intracoronary bradykinin. In 10 experiments epicardial bradykinin $(500 \mu \mathrm{g})$ was applied to a $2 \times 2-\mathrm{cm}$ gauze placed on the anterior wall of the left ventricle. Intracoronary bradykinin $(100 \mu \mathrm{g})$ was injected through the coronary cannula.

In 3 additional experiments responses of arterial pressure and RSNA to escalating doses of intracoronary bradykinin were measured before and after TMLR. The doses of bradykinin used for these experiments were 1, 10, and $100 \mu \mathrm{g}$. For all experiments, the order of bradykinin administration was randomized. Adequate time (10-15 minutes) between bradykinin administrations was allowed for arterial pressure and RSNA to return to baseline levels. After TMLR, the animal was allowed to stabilize for 45 minutes before responses to bradykinin were measured for a final time.

\section{Pathologic Analysis}

Multiple samples from the lased regions of 2 formalin-fixed canine hearts were examined microscopically to determine the anatomic effects of TMLR on cardiac neural structures. Five sections were randomly taken from each heart: 3 sections from the cardiac base and 2 from the cardiac apex. Each section contained at least 2 lased channels. Full-thickness myocardial sections were taken from the epicardium to the endocardium along the length of the lased channels. Multiple levels of 5- $\mu \mathrm{m}$ sections were examined microscopically by means of conventional hematoxylin and eosin staining. In addition, histochemical staining with Bielschowsky stain was performed to visualize the axon fibers of the nerves. ${ }^{23}$

\section{Data Analysis}

Arterial pressure, raw RSNA, and integrated RSNA were recorded continuously on an electrostatic recorder (model ES1000; Gould Electronics Inc, Eastlake, Ohio) during bradykinin administration. Baseline measurements were made immediately before bradykinin administration. Repeat measurements were made during the peak reflex changes in arterial pressure and RSNA elicited by bradykinin. In most cases these peak changes occur within 10 to 20 seconds for intracoronary bradykinin and within 15 to 45 seconds for epicardial bradykinin. Because renal nerve recordings were made from multiunit nerves in which the number of active fibers is variable between experiments, the reflex changes in nerve traffic were expressed in terms of percentage changes from baseline values. 


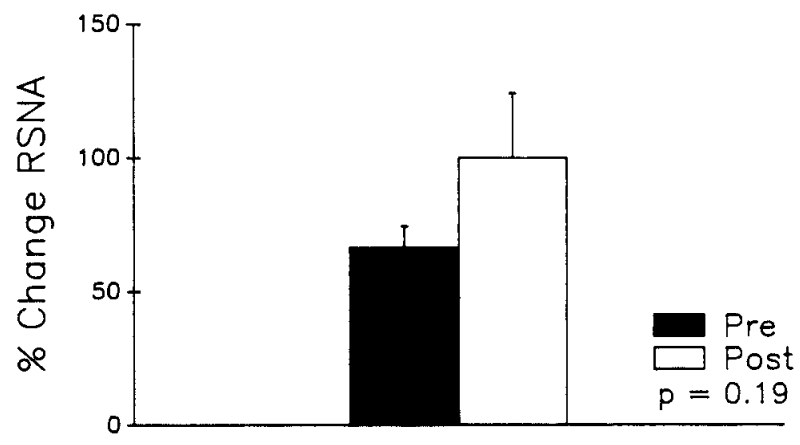

Figure 2. Mean \pm SEM percentage changes in RSNA in response to epicardial bradykinin $(500 \mu \mathrm{g})$ measured before (filled bar) and after (open bar) TMLR $(\mathrm{n}=10)$.

Observations for all experiments were combined, and mean \pm SEM values were calculated. A paired $t$ test was used to determine whether TMLR caused significant differences in the responses of arterial pressure and RSNA to epicardial and intracoronary bradykinin.

\section{Results}

Figure 1 shows an original record from a representative experiment illustrating the responses to epicardial bradykinin. Responses were measured before (top panel) and after (bottom panel) TMLR. In the baseline state application of bradykinin to the epicardium elicits reflex excitatory responses manifested by an increase in arterial pressure and an increase in RSNA. After TMLR, the responses of arterial pressure and RSNA to epicardial bradykinin are unchanged.

\section{Responses to Epicardial Bradykinin}

Figure 2 shows the mean percentage of changes in RSNA in response to epicardial bradykinin for all experiments. Before TMLR, activation of left ventricular receptors with sympathetic afferent fibers by epicardial bradykinin elicited reflex increases in RSNA. After TMLR, these reflex increases in RSNA were not significantly changed (before TMLR, 66\% $\pm 8 \%$; after TMLR, $100 \% \pm 24 \% ; P=.19$ ). Mean arterial pressure significantly increased in response to epicardial bradykinin both before and after TMLR (before TMLR, $18 \pm 3 \mathrm{~mm} \mathrm{Hg}$; after TMLR, $19 \pm 4 \mathrm{~mm} \mathrm{Hg} ; P=$ $.83)$. Baseline mean arterial pressures measured immediately before epicardial bradykinin administration were significantly lower after than before TMLR (before TMLR, $119 \pm 8 \mathrm{~mm} \mathrm{Hg}$; after TMLR, $101 \pm 6 \mathrm{~mm} \mathrm{Hg} ; P=.01)$. However, there were no significant differences in the level of baseline RSNA (before TMLR, $54 \pm 7$ impulses/s; after TMLR, $61 \pm 9$ impulses/s; $P=.46$ ).

\section{Responses to Intracoronary Bradykinin}

Figure 3 shows the mean percentage of changes in RSNA in response to intracoronary bradykinin. Before TMLR, intra-

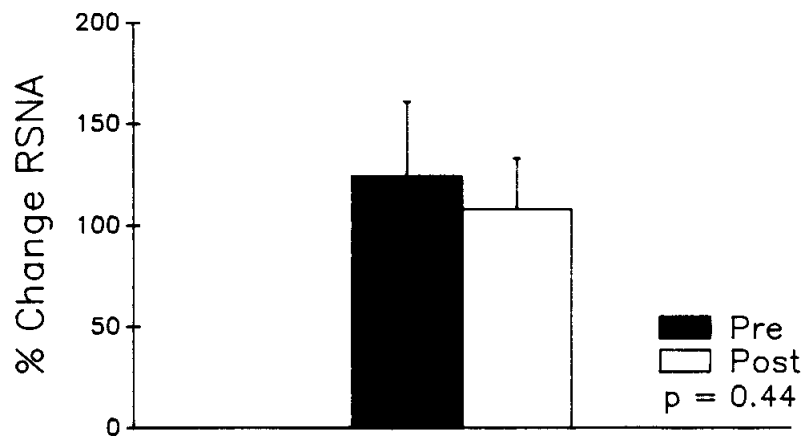

Figure 3. Mean \pm SEM percentage changes in RSNA in response to intracoronary bradykinin (100 $\mu \mathrm{g})$ measured before (filled bar) and after (open bar) TMLR ( $\mathrm{n}=10)$.

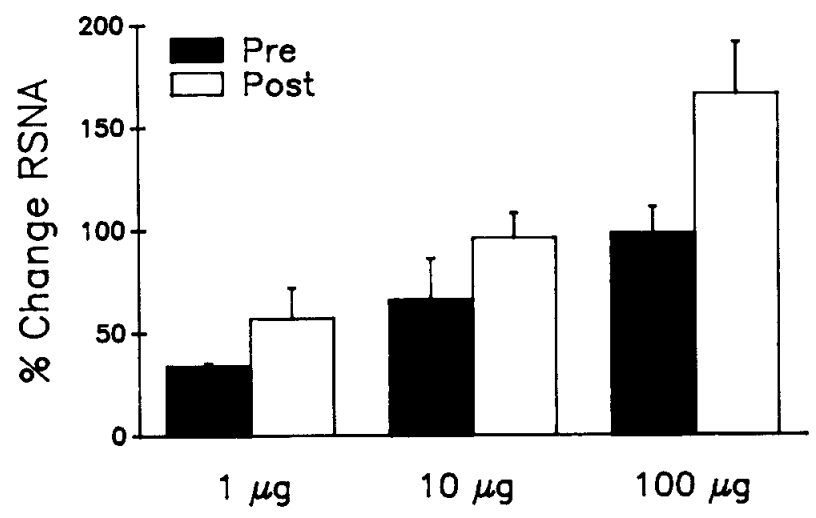

Figure 4. Mean \pm SEM percentage changes in RSNA in response to varying doses of intracoronary bradykinin $(1,10$, and $100 \mu \mathrm{g})$ measured before (filled bars) and after (open bars) TMLR $(n=3)$.

coronary injection of bradykinin resulted in large reflex increases in RSNA. After TMLR, there was no significant difference in the renal-nerve responses to activation of left ventricular sympathetic afferents by intracoronary bradykinin (before TMLR, 124\% $\pm 37 \%$; after TMLR, $108 \% \pm 25 \% ; P=.44)$. As opposed to epicardial bradykinin, intracoronary injection elicited significant decreases in mean arterial pressure both before and after TMLR (before TMLR, $-56 \pm 5 \mathrm{~mm} \mathrm{Hg}$; after TMLR, $-44 \pm 5 \mathrm{~mm} \mathrm{Hg} ; P=$ .03). Baseline mean arterial pressures observed before intracoronary bradykinin were also significantly lower after than before TMLR (before TMLR, $126 \pm 7 \mathrm{~mm} \mathrm{Hg}$; after TMLR, $106 \pm 6 \mathrm{~mm} \mathrm{Hg} ; P=.01)$. However, there were no significant differences in the level of baseline RSNA (before TMLR, $55 \pm 7$ impulses/s; after TMLR, $53 \pm 7$ impulses/s; $P=.73)$.

Figure 4 shows the mean renal nerve responses to escalating doses of intracoronary bradykinin in 3 additional experiments. An incremental relationship was observed between increasing doses of bradykinin and reflex increases 

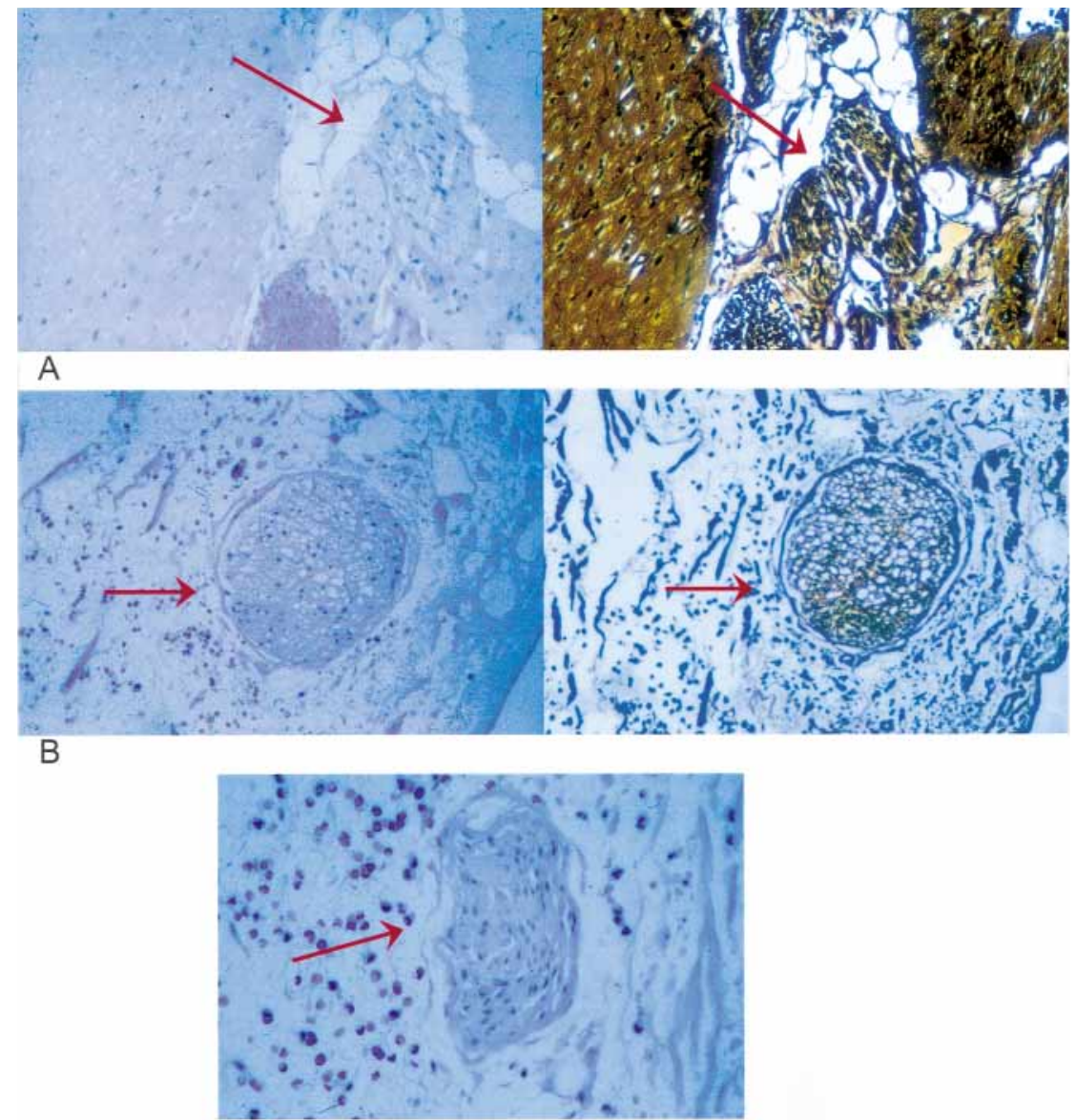

C

Figure 5. Representative photomicrographs of pathologic specimens obtained from lased hearts. Panel A shows both hematoxylin and eosin (left) and Bielschowsky (right) stains of a neurovascular bundle containing intact neural structures (arrows) remote from a lased channel (original magnification, 50 $\times$ ). Panel B shows hematoxylin and eosin (left) and Bielschowsky (right) stains of a damaged nerve (arrow) within a region of laser-induced myocardial damage (original magnification, 50×). Panel $\mathrm{C}$ shows hematoxylin and eosin stain of an undamaged nerve within the zone of laser-induced myocardial inflammation (original magnification, 100 $\times$ ).

in RSNA. TMLR had no discernable effect on the increases in RSNA in response to any dose of intracoronary bradykinin. Escalating doses of intracoronary bradykinin also caused progressive decreases in mean arterial pressures (data not shown). These changes in pressure were not altered by TMLR.

\section{Pathologic Analysis}

Figure 5 shows representative photomicrographs illustrating the effects of TMLR on cardiac neural structures. In areas remote from the lased channels, intact neural structures were observed (Figure 5, A). In areas showing evidence of laser-induced myocardial damage, there was also evidence of neural damage, with edema and vacuolization (Figure 5, $B)$. However, undamaged nerve fibers were also present in the vicinity (within $1 \mathrm{~mm}$ ) of laser-induced myocardial damage (Figure 5, $C$ ).

\section{Discussion}

The major finding of our study is that reflexes mediated by left ventricular receptors with sympathetic afferent fibers in response to chemical activation are unaffected by TMLR. Both intracoronary and epicardial bradykinin elicit similar degrees of reflex sympathoexcitation before and after TMLR. These results indicate that the receptors that are believed to represent the afferent pathway for the perception of anginal pain remain functional immediately after TMLR.

Although TMLR has been shown to alleviate anginal pain in patients with advanced coronary artery disease, the mechanism for this benefit remains uncertain. Several 
mechanisms have been proposed, including direct myocardial perfusion through the lased channels, laser-induced neovascularization, cardiac denervation, and a placebo effect. Cardiac denervation as a potential mechanism for pain relief is a reasonable hypothesis. Laser energy is known to produce thermal damage and tissue vaporization in the treated area. ${ }^{24}$ This could damage any neural structures in the immediate vicinity. Cardiac nociception and anginal pain are believed to be related to mechanical and chemical activation of left ventricular receptors with sympathetic afferent fibers. ${ }^{6,7}$ If TMLR results in cardiac sympathetic deafferentation, then the perception of anginal pain should be prevented or reduced.

Clinical and experimental investigations done by others support the neural hypothesis for pain relief after TMLR. Anatomic evidence of cardiac sympathetic denervation has been observed after TMLR in human subjects and in experimental animals. Al-Sheikh and colleagues ${ }^{18}$ have demonstrated cardiac sympathetic neuronal injury as manifested by decreased myocardial uptake of carbon 11-labeled hydroxyephedrine in patients who had previously undergone TMLR. ${ }^{18}$ This tracer is a catecholamine analog that reflects norepinephrine uptake-1 and vesicular storage mechanisms of viable sympathetic nerve terminals. ${ }^{25}$ In dogs who had previously been treated with TMLR, Kwong and colleagues ${ }^{17}$ demonstrated a reduced concentration of tyrosine hydroxylase in the treated myocardium. This enzyme is involved in the synthesis of norepinephrine from tyrosine and is believed to be a specific marker for efferent sympathetic nerve terminals. ${ }^{26}$

Although these studies provide anatomic evidence for cardiac sympathetic denervation, the markers used are not specific for cardiac receptors with sympathetic afferent fibers. Furthermore, these anatomic observations provide no functional information about the ability of left ventricular sympathetic receptors to transmit afferent traffic to the brain and spinal cord. Kwong and colleagues ${ }^{17}$ did assess the functional integrity of cardiac reflexes after TMLR. In anesthetized dogs they demonstrated that changes in arterial pressure elicited by epicardial application of bradykinin were abolished 2 weeks after TMLR. On the basis of this finding, they concluded that cardiac deafferentation occurred in the laser-treated areas.

In our experiments we were unable to show functional evidence of cardiac deafferentation after TMLR. The discrepancy between the experimental observations of Kwong and colleagues ${ }^{17}$ and the results of our study could be related to differences in methodology. For instance, Kwong and colleagues studied animals with all autonomic reflexes intact. This represents a potential problem because responses mediated by left ventricular receptors with sympathetic afferent fibers are heavily influenced by other neurocirculatory reflexes, such as the sinoaortic baroreflex and the vagal cardiopulmonary reflex. ${ }^{27}$ This is particularly true when bradykinin is used as an agonist because bradykinin has been shown to activate cardiac receptors with both vagal and sympathetic afferent fibers. ${ }^{28}$

Our experiments were performed in animals with sinoaortic denervation and vagotomy. This experimental preparation was used to facilitate the investigation of reflex responses mediated by left ventricular receptors with sympathetic afferent fibers. Sinoaortic denervation prevented changes in arterial pressure associated with bradykinin administration from affecting the reflex responses mediated by cardiac sympathetic afferents. Vagotomy prevented the activation of cardiac vagal afferents by bradykinin from contributing to these reflex responses. Thus, elimination of the effects of the sinoaortic baroreflex and the vagal cardiopulmonary reflex ensured that reflex changes in sympathetic outflow elicited by bradykinin were mediated by left ventricular receptors with sympathetic afferent fibers.

Kwong and colleagues ${ }^{17}$ used changes in arterial pressure to measure the response to epicardial bradykinin. We measured the reflex effects of bradykinin administration by means of direct recording of efferent sympathetic nerve traffic. This technique provides a more quantitative and rigorous assessment of the reflex changes in sympathetic outflow from the central nervous system, particularly in response to activation of cardiac receptors.

Perhaps most important, Kwong and associates ${ }^{17}$ studied responses to bradykinin 2 weeks after TMLR. We assessed the effects of TMLR on reflexes mediated by left ventricular receptors with sympathetic afferent fibers in the acute experimental model. This enabled us to use each animal as its own control. In our experience there is significant variability between animals in the magnitude of reflex sympathoexcitation elicited by bradykinin. This variability could have a significant confounding effect on the results of a chronic protocol, in which a separate control group would be required. However, the results of the present study cannot exclude the possibility that cardiac deafferentation occurs days or weeks after TMLR, as suggested by the data of Kwong and colleagues. Our clinical observation has been that patients note improvement in anginal status immediately after TMLR. Thus, if cardiac deafferentation plays a mechanistic role in the immediate relief of angina, then evidence of this deafferentation should be apparent immediately.

Of note, the results of our study are in agreement with the observations made by Hirsch and colleagues. ${ }^{29}$ They made direct recordings from intrinsic cardiac afferent neurons in the ventral right atrial ganglionated plexus and were unable to demonstrate an acute effect of TMLR on the increased neuronal activity elicited by epicardial application of bradykinin or veratridine. They also found that the responses to electrical stimulation of efferent sympathetic and parasympathetic nerves to the heart were unchanged 
after TMLR. Our results extend their observations because we measured the integrity of the entire sympathetic afferent reflex arc, finding that is was fully functional after TMLR.

The pathologic analysis is consistent with these functional data, which indicate that TMLR does not significantly alter neural responses. For instance, although nerves in close proximity to the lased channels exhibited evidence of neuronal damage, nerves that were distant from the lased regions were undamaged. Of note, undamaged nerves were also observed within the inflammatory zone, resulting from laser-induced myocardial trauma. We speculate that this latter finding is related to nonuniform propagation of acoustic shock waves generated by laser energy, variable susceptibility of cardiac tissue to the effects of laser energy, or both. ${ }^{30}$ These observations indicate that any cardiac structure exposed directly to laser energy may be potentially damaged. However, the pathologic analysis combined with the results of the reflex studies demonstrate that TMLR does not cause sufficient neuronal damage to eliminate or attenuate responses mediated by cardiac sympathetic afferents.

In this study bradykinin was used as an experimental tool to activate cardiac sympathetic afferents and to elicit a reflex response that could be quantitated. High doses of bradykinin were used for this purpose. In our experience these doses of bradykinin are well tolerated in the anesthetized canine model, and they consistently produce a measurable reflex response. It is possible that TMLR may have subtle effects on cardiac sympathetic afferents, which might only be apparent at lower doses of bradykinin. Responses to several doses of intracoronary bradykinin were measured in a subset of experiments to exclude this possibility. A doseresponse relationship between the amount of bradykinin injected and the magnitude of reflex sympathoexcitation was observed. TMLR did not attenuate the response to any dose of intracoronary bradykinin. The results of this subset of experiments provide further evidence that reflexes mediated by cardiac sympathetic afferents remain functional after TMLR.

A limitation of this study is that experiments were performed in normal canine hearts and not in models of chronic ischemia or hibernating myocardium. These studies represent our initial effort to study the effects of TMLR on cardiac sympathetic afferents. If TMLR relieves angina by causing cardiac deafferentation, the presumed mechanism would be laser-induced thermal damage to cardiac neural structures. This effect of laser energy should be similar in both ischemic and normal myocardium. Nevertheless, our experimental results do not exclude the possibility that TMLR has different effects in an ischemic model.

In summary, the results of our acute study indicate that holmium:YAG laser treatment does not result in sympathetic deafferentation of the treated areas. Reflex increases in sympathetic outflow in response to activation of left ven- tricular receptors with sympathetic afferent fibers were not diminished significantly by TMLR. These results provide functional evidence that these receptors remain intact after TMLR and are capable of transmitting afferent input to the brain and spinal cord. Because these receptors are considered to be the cardiac nociceptors, these data do not support the neural hypothesis for the relief of angina by TMLR.

We thank Eclipse Surgical Technologies Inc, Sunnyvale, California, for providing the laser catheters used in this study; James A. Arrowood, MD, for his thoughtful review of the manuscript; and Shirley McCray for her clerical assistance.

\section{References}

1. Horvath KA, Cohn LH, Cooley DA, Crew JR, Frazier OH, Griffith BP, et al. Transmyocardial laser revascularization: results of a multicenter trial with transmyocardial laser revascularization used as sole therapy for end-stage coronary artery disease. $J$ Thorac Cardiovasc Surg. 1997;113:645-53.

2. Schofield PM, Sharples LD, Caine N, Burns S, Tait S, Wistow T, et al. Transmyocardial laser revascularization in patients with refractory angina: a randomised controlled trial. Lancet. 1999;353:519-24.

3. Allen KB, Dowling RD, Fudge TL, Schoettle GP, Selinger SL, Gangahar DM, et al. Comparison of transmyocardial revascularization with medical therapy in patients with refractory angina. $N$ Engl J Med. 1999;341:1029-36.

4. Frazier OH, March RJ, Horvath KA. Transmyocardial revascularization with a carbon dioxide laser in patients with end-stage coronary artery disease. $N$ Engl J Med. 1999;341:1021-8.

5. Horvath KA, Mannting F, Cummings N, Shernan SK, Cohn LH. Transmyocardial laser revascularization, operative techniques, and clinical results at two years. J Thorac Cardiovasc Surg. 1996;111:1047-53.

6. White JC. Cardiac pain: anatomic pathways and physiologic mechanisms. Circulation. 1957; 16:644-55.

7. Baker DG, Coleridge HM, Coleridge JCG, Nerdrum T. Search for a cardiac nociceptor: stimulation by bradykinin of afferent sympathetic nerve endings in the cat. J Physiol. 1980;306:519-36.

8. Barber MJ, Mueller TM, Davies BG, Zipes DP. Phenol topically applied to canine left ventricular epicardium interrupts sympathetic but not vagal afferents. Circ Res. 1984;55:532-44.

9. Minisi AJ, Thames MD. Activation of cardiac sympathetic afferents during coronary occlusion: evidence for reflex activation of the sympathetic nervous system during transmural myocardial ischemia in the dog. Circulation. 1991;84:357-67.

10. Minisi AJ, Thames MD. Distribution of left ventricular sympathetic afferents demonstrated by reflex responses to transmural myocardial ischemia and to intracoronary and epicardial bradykinin. Circulation. 1993;87:240-6.

11. Malliani A, Recordati G, Schwartz PJ. Nervous activity of afferent cardiac sympathetic, fibres with atrial and ventricular endings. $J$ Physiol. 1973;229:457-69.

12. Lombardi F, Della Bella P, Casati R, Malliani A. Effects of intracoronary administration of bradykinin on the impulse activity of afferent sympathetic unmyelinated fibers with left ventricular endings in the cat. Circ Res. 1981;48:69-75.

13. Uchida Y, Kamisaka K, Murao S, Ueda H. Mechanosensitivity of afferent cardiac sympathetic nerve fiber. Am J Physiol. 1974;226:1088-93.

14. Brown A. Cardiac reflexes. In: Berne RM, editor. Handbook of physiology: the heart. Washington, DC: American Physiological Society: 1983. p. 667-89.

15. Bishop VS, Malliani A, Thoren P. Cardiac mechanoreceptors. In: Shepherd JT, Abboud FM, editors. Handbook of physiology: peripheral circulation and organ blood flow. Washington, DC: American Physioiogical Society; 1983. p. 497-555.

16. Malliani A. Afferent cardiovascular sympathetic nerve fibers and their function in the neural regulation of the circulation, In: Hainsworth R, 
Kidd C, Linden RJ, editors. Cardiac receptors. Cambridge, UK: Cambridge University Press; 1979. p. 319-38.

17. Kwong KF, Kanellopoulos GK, Nickols JC, Pogwizd SM, Saffitz JE, Schuessler RB, et al. Transmyocardial laser treatment denervates canine myocardium. J Thorac Cardiovasc Surg. 1997;114:883-9.

18. Al-Sheikh T, Allen KB, Straka SP, Heimansohn DA, Fain RL, Hutchins GD, et al. Cardiac sympathetic denervation after transmyocardial laser revascularization. Circulation. 1999;100:135-40.

19. Thames MD, Abboud FM. Interaction of somatic and cardiopulmonary receptors in control of renal circulation. Am J Physiol. 1979;237:H560-5.

20. Thames MD, Miller BD, Abboud FM. Baroreflex regulation of renal nerve activity during volume expansion. Am J Physiol. 1982;243:H810-4.

21. Minisi AJ, Dibner-Dunlap M, Thames MD. Vagal cardiopulmonary baroreflex activation during phenylephrine infusion. Am J Physiol. 1989;257:R1147-53

22. Felder RB, Thames MD. The cardiocardiac sympathetic reflex during coronary occlusion in anesthetized dogs. Circ Res. 1981;48:685-92.

23. Mirra SS, Hart MN, Terry RD. Making the diagnosis of Alzheimer's disease. Arch Pathol Lab Med. 1993;117:132-44.

24. Hardy RI, Bove KE, James FW, Kaplan S, Goldman L. A histologic study of laser-induced transmyocardial channels. Lasers Surg Med. 1987;6:563-73.
25. Allman KC, Wieland DM, Muzik O, Degrado TR, Wolfe ER Jr, Schwaiger M. Carbon-11 hydroxyephedrine with positron emission tomography for serial assessment of cardiac adrenergic neuronal function after acute myocardial infarction in humans. J Am Coll Cardiol. 1993;22:368-75.

26. Wooten GF, Coyle JT. Axonal transport of catecholamine synthesizing and metabolizing enzymes. J Neurochem. 1973;20:1361-71.

27. Felder RB, Thames MD. Interaction between cardiac receptors and sinoaortic baroreceptors in the control of efferent cardiac sympathetic nerve activity during myocardial ischemic in dogs. Circ Res. 1979;45:728-36.

28. Kaufman MP, Baker BG, Coleridge HM, Coleridge JCG. Stimulation by bradykinin of afferent vagal C-fibers with chemosensitive endings in the heart and aorta of the dog. Circ Res. 1980;46:476-84.

29. Hirsch GM, Thompson GW, Arora RC, Hirsch KJ, Sullivan JA, Armour JA. Transmyocardial laser revascularization does not denervate the canine heart. Ann Thorac Surg. 1999;68:460-9.

30. van Gemert MJC, Welch AJ, Jacques SL, Cheong WF, Star WM. Light distribution, optical properties, and cardiovascular tissues. In: Abela GS, editor. Lasers in cardiovascular medicine and surgery: fundamentals and techniques. Dordrecht, The Netherlands: Kluwer Academic Publishers; 1990. p. $99-110$.

\section{Targeted}

The Journal of Thoracic and Cardiovascular Surgery gives you two tables of contents.

The condensed table of contents tells you at a glance what topics and authors are presented each month. The expanded table of contents gives you a brief abstract of each article. You select only those articles of most interest to you for further reading. 